\title{
FOVEAL INVOLVEMENT AND LACK OF VISUAL RECOVERY IN APMPPE ASSOCIATED WITH UNCOMMON FEATURES
}

\author{
S. PAGLIARINI, B. PIGUET, T. J. FFYTCHE and A. C. BIRD \\ London
}

\begin{abstract}
SUMMARY
Acute posterior multifocal placoid pigment epitheliopathy (APMPPE) is commonly believed to be a benign disease with excellent visual prognosis. Identification of cases with poor visual outcome prompted this retrospective study of 33 eyes of 18 patients with this disorder. Loss of visual acuity at presentation was recorded in 25 eyes $(76 \%), 22$ of which had lesions at the fovea. Visual acuity quickly returned to normal or near normal levels (even when it was as poor as counting fingers at entry) in all but 7 eyes of 7 patients, in which visual acuity failed to recover to better than 6/24 over a period of several months. All these eyes had poor acuity and foveal involvement when first seen, and at least one of the following atypical features: age older than 60 years, unilaterality, an interval before involvement of the second eye of at least 6 months, recurrence of the disease, leakage from choroidal vein. One additional patient whose foveae were initially not involved lost vision in one eye because of the development of choroidal neovascularisation. Caution should be exercised in giving a prognosis in cases when the fovea is involved and the acuity markedly reduced, particularly if one or more atypical features is present.
\end{abstract}

Characteristically, acute posterior multifocal placoid pigment epitheliopathy (APMPPE) affects young healthy subjects, in one-third of cases after a prodromal flu-like syndrome. ${ }^{1-5}$ The cause of the disease is unknown. Fundus involvement is usually bilateral ${ }^{4,6,7}$ and is characterised by multiple postequatorial deep yellow-white patches at the level of the retinal pigment epithelium that on fluorescein angiography show early hypofluorescence followed by late bright staining. ${ }^{6}$ The fundus lesions heal rapidly, over a period of weeks or months, ${ }^{2,6-8}$ leaving focal scars with various degrees of pigmen-

Correspondence to: A. C. Bird, Institute of Ophthalmology, Moorfields Eye Hospital, City Road, London EC1V 2PD, UK. Fax: 0712519350. tary change at the level of the retinal pigment epithelium. ${ }^{6-8}$ These do not change with time, ${ }^{3}$ although exceptions have been reported. ${ }^{9-11}$ Healing is accompanied or followed by visual recovery to final acuity levels of $6 / 9$ or better, ${ }^{12}$ even in cases in which foveal involvement had initially caused profound visual loss. ${ }^{2,4,8}$

Although the majority of published reports reaffirm the benign nature of APMPPE with respect to visual outcome, cases with foveolar involvement and poor final visual acuity are recorded in a number of reported series. , $^{3,8,10,12-17}$ It also appears that the clinical manifestations of APMPPE are more variable than originally thought. Recurrences $^{14,18}$ and optic disc swelling $9,15,19,20$ occur and may be associated with poor outcome. $^{9,14,15}$ Extraocular ${ }^{4,19,21-27}$ and ocular structures other than retinal pigment epithelium and choroid $^{7,9,10,12,14,15,19,20,28}$ can be involved, and the sensory retina overlying placoid lesions may detach $^{4,12,19,29}$ resulting in clinical pictures resembling those seen in Harada disease. ${ }^{30,31}$

Our recent observation of poor visual recovery in eyes with APMPPE involving the fovea raised the possibility that an unfavourable outcome in such cases is not rare. The additional observation that atypical features such as unilaterality and advanced age were present in these cases led us to review a series of patients with placoid pigment epitheliopathy.

\section{MATERIALS AND METHODS}

The clinical records of 32 patients who received a diagnosis of APMPPE in the Retinal Diagnostic Department of Moorfields Eye Hospital between January 1980 and January 1992 were located and reviewed. The initial diagnosis was confirmed by the presence of documented patches of deep yellowcream discolouration at the level of the retinal pigment epithelium in the posterior pole of at least 


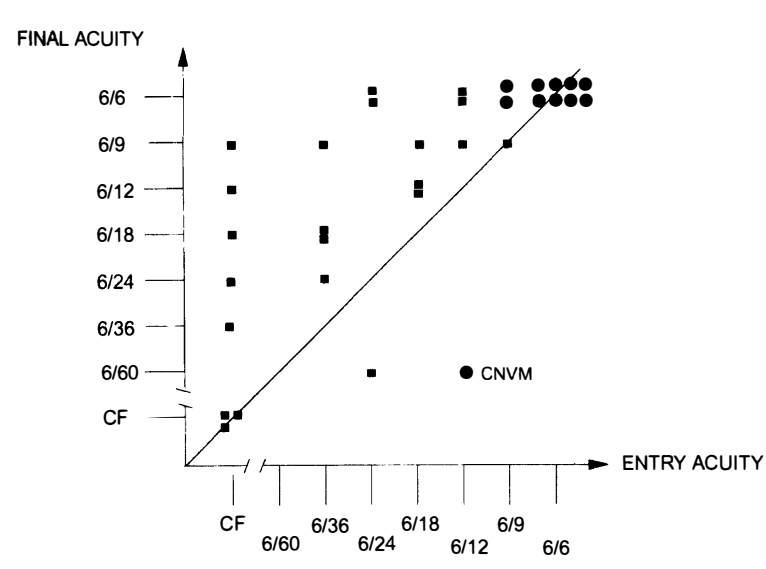

Fig. 1. Scattergram of the initial acuity and final acuity in 33 eyes of 18 patients. Points above the no-change line represent an eye with improved visual acuity. A square represents an eye with foveal involvement and a circle an eye without foveal involvement.

one eye, and the typical fluorescein pattern of initial hypofluorescence followed by late hyperfluorescence. The minimal length of follow-up required was that necessary for the disease to reach an inactive cicatricial stage, defined as a varying degree of atrophy and mottling of pigment epithelium or recovery to good visual acuity. Patients with multiple recurrences, a 'jigsaw' pattern of lesions radiating from the optic nerve or lesions at different stages of evolution were not entered in the review in order to exclude patients with serpiginous choroidopathy. Excluded also were cases with serous detachment of the neurosensory retina overlying the placoid lesions because of possible confusion with Harada disease. Features such as unilaterality, asynchronous involvement of the two eyes, older age and recurrences did not exclude patients from this review.

Age, sex, duration of symptoms, entry and final visual acuity, foveal involvement and duration of follow-up were extracted from clinical records and tabulated.

\section{RESULTS}

Of the 32 clinical records, 12 were discarded because of inadequate data or follow-up and 2 because of inappropriate diagnosis, leaving 18 patients for analysis. Unilateral involvement was observed in 3 patients so that 33 eyes were available for analysis. The period of review was up to 1 month for 8 patients all of whom recovered vision, between 1 and 6 months for 4, and from 6 to 60 months for 6 patients. The male/female ratio was $7 / 10$ and the mean age was 36 years (range 17-61 years).

Of the 15 cases with bilateral disease, the second eye was involved within 4 weeks in 11. In 2 patients the interval before involvement of the second eye was longer than 6 months. Foveal involvement at entry was found in 22 eyes $(66 \%)$ and was responsible for visual loss in all of them; 15 of these eyes had entry acuity reduced to $6 / 24$ or less (Fig. 1). When the fovea was not involved (11 eyes) visual acuity was $6 / 12$ or better at entry and with one exception $6 / 6$ or better at the final visit. Recovery of visual acuity was generally fast. Partial resolution of lesions was already present in a number of patients within 2 weeks of the initial symptoms. As soon as the lesions healed and acuity reached normality or stability, patients were discharged. In 7 eyes of 7 patients visual acuity failed to recover to levels better than $6 / 24$ during the period of review (mean followup 16 months, median 7 months, range 3-60 months), although in all cases the fellow eye retained visual acuity of 6/12 or better (Fig. 1). In 1 eye of 1 patient visual acuity decreased because of choroidal neovascularisation. Foveal involvement and profound visual loss at entry were common to all other eyes that failed to recover vision, although these features did not preclude rapid recovery to normal visual acuity.

Analysis of the influence of size of subfoveal lesions on outcome was inconclusive. Large plaques covering an area around the fovea equal or greater than 1 disc diameter, and small subfoveal lesions, were both associated with poor visual outcome. Furthermore, large plaques proved to be compatible with rapid healing and recovery of vision (Fig. 2a-f).

The 7 cases ( 7 eyes of 7 patients) with poor outcome had one or more features which are considered unusual for APMPPE, and were not observed in the group with good outcome. These were: unilaterality (3); recurrence of the disease (3); interval greater than 6 months before involvement of the second eye (2); leakage from large choroidal vessels (1) (Fig. 3 e-g), age older than 60 years (1). Although the oldest patient had a poor final acuity, the mean age for those with poor outcome (32 years, SD 14.1) was not greater than in those with good vision (38 years, SD 12.5). Gender did not differ between the two groups.

\section{DISCUSSION}

Since its original description ${ }^{6}$ APMPPE has been considered a benign condition characterised by rapid and almost complete recovery of visual acuity, 2,6-8 although residual scotomata or colour vision defects can persist as long-term sequelae. ${ }^{3}$ A study of photoreceptor function in APMPPE has shown variable and frequently incomplete recovery of photopigment density and regeneration time. ${ }^{17}$ Our study shows that the concept of benignity of APMPPE does not apply to all cases, particularly when there is foveal involvement and poor acuity (6/24 or less). Although all cases with a poor outcome had these features, poor initial acuity did not preclude good recovery. The proportion of eyes with foveal involvement $(66 \%)$ was similar to other 


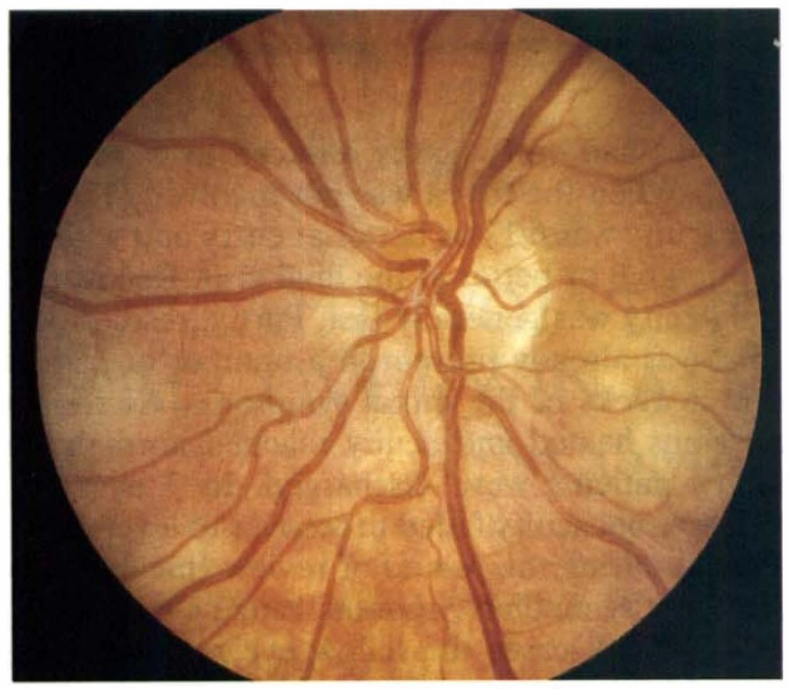

(a)

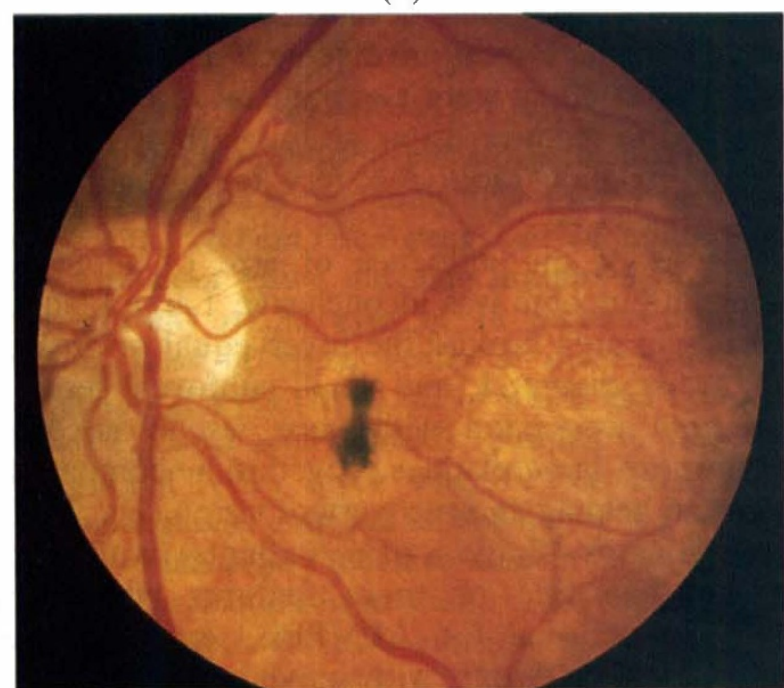

(c)

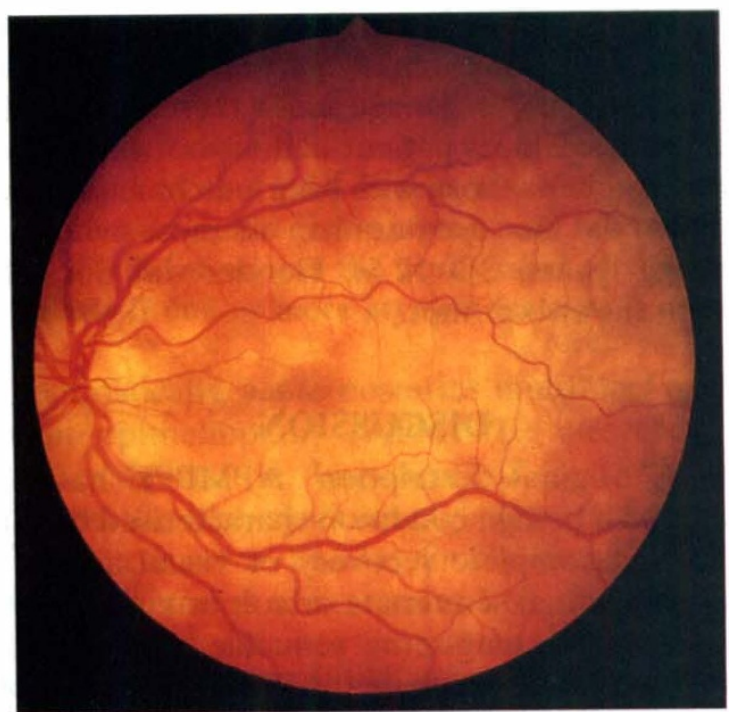

(e)

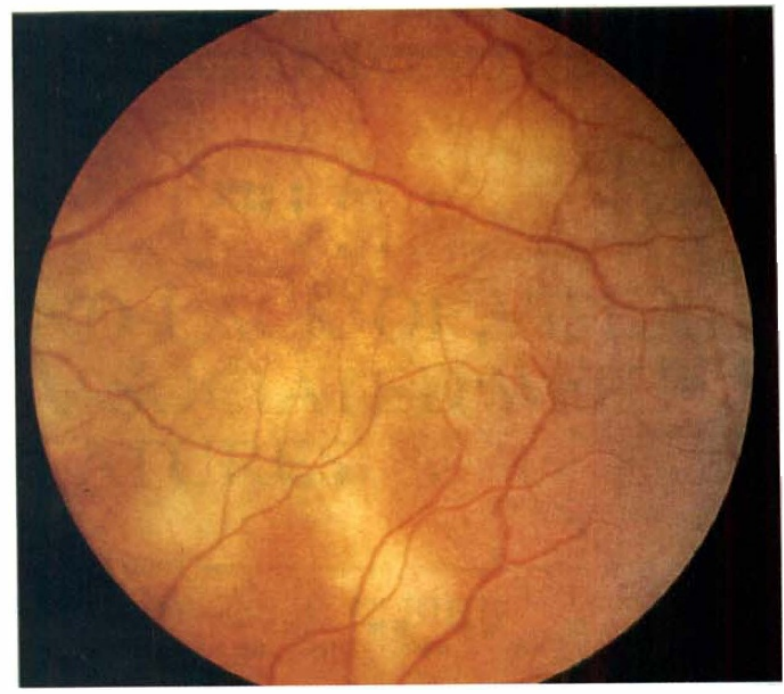

(b)

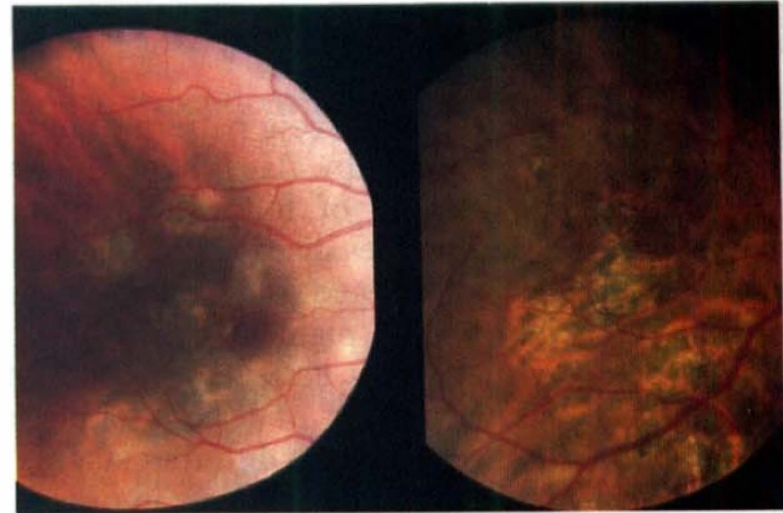

(d)

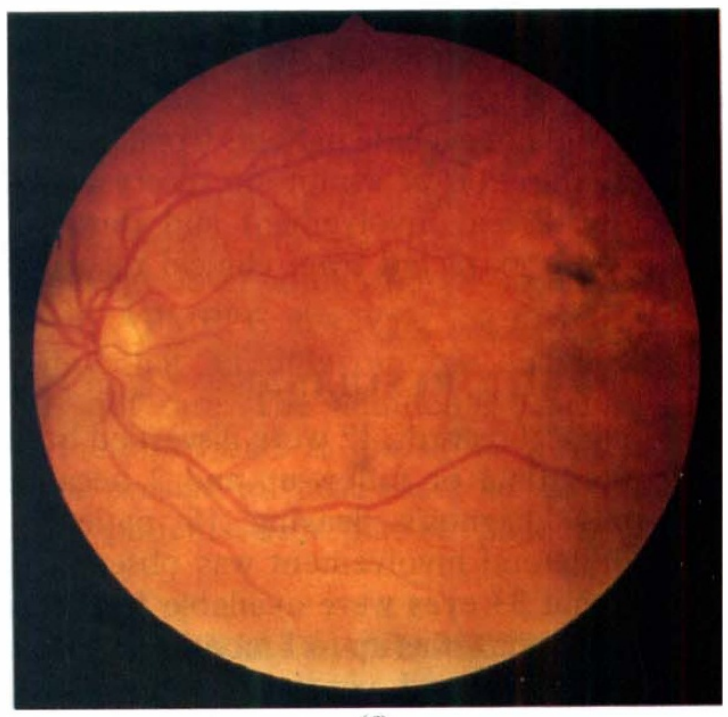

(f)

Fig. 2. The variable influence of size of subfoveal lesions on outcome. (a)-(c) Man, age 35 years, with involvement of the left eye only. (a) At presentation there are yellow placoid lesions around the optic disc. (b) One week later lesions have spread to form a large macular plaque, and visual acuity was reduced to counting fingers at $50 \mathrm{~cm}$. (c) Two years later the visual acuity was $3 / 60$ and there was atrophy of the pigment epithelium at the macula. (d) Man, age 30 years. Left: Multifocal placoid lesions were seen in the right eye 6 months after a similar episode in the left eye. A small lesion was centred on the fovea and the visual acuity was reduced to hand movements. Right: Seven months later multiple areas of atrophy of the retinal pigment epithelium and choriocapillaris had replaced the initial placoid lesions. There was limited involvement of the fovea but the visual acuity was counting fingers. (e) and (f) Woman, age 27 years, left eye. (e) A large subfoveal placoid lesion was seen at presentation when the visual acuity was reduced to 4/60. (f) Six weeks later the lesion had regressed leaving minimal derangement of the retinal pigment epithelium. The visual acuity returned to $6 / 6$. 


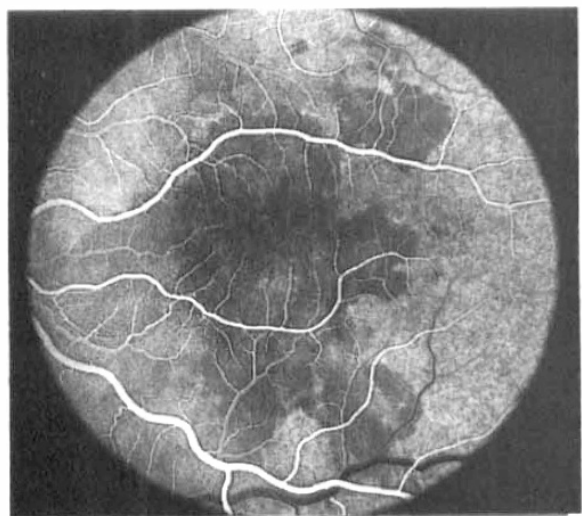

(a)

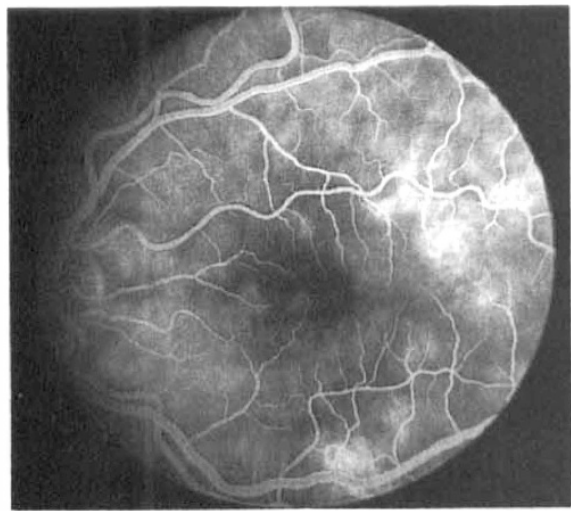

(c)

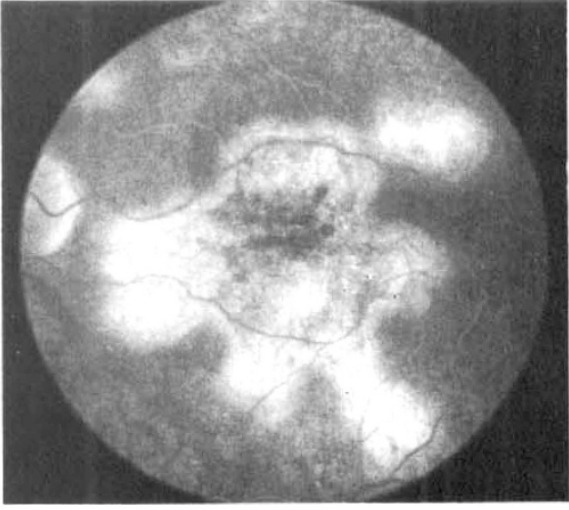

(b)

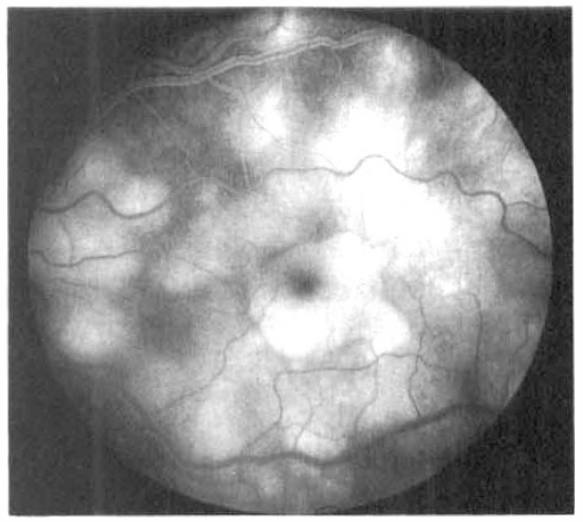

(d)

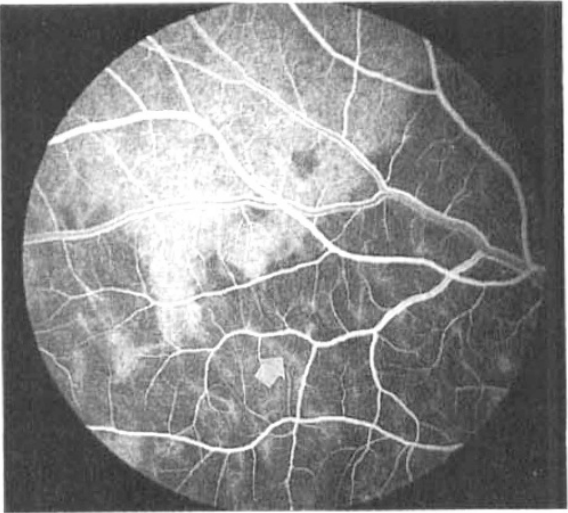

(c)

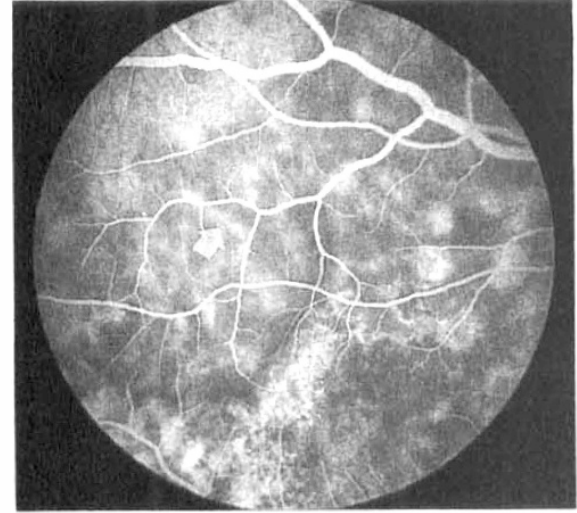

(f)

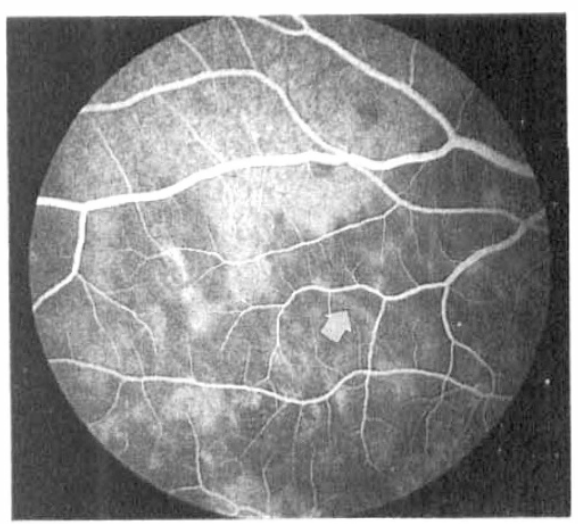

$(g)$

Fig. 3. (a) and (b) Fluorescein angiogram of the patient illustrated in Fig. 2a, b, showing a large hypofluorescent placoid lesion centred on the fovea in the early phase of the fluorescein study at presentation $(a)$, which fluoresced brightly late in the study $(b)$. (c) and $(d)$ Fluorescein angiogram of the patient illustrated in Fig. $2 e$, $f$, showing early hypofluorescence (c) and late hyperfluorescence (d) of the macular lesions. (e)-(g) Woman, age 17. The early phase of the angiogram shows confluent hypofluorescence (e). Details of choroidal vessels are visible throughout the study $(f, g)$. One choroidal vessel (arrow) shows increased fluorescence and blur of its walls through the sequence, a phenomenon interpreted as inflammatory leakage. The straight course of the vessel indicates it is a choroidal vein. 
studies $^{4,11}$ but the figure of $24 \%$ of eyes with unfavourable outcome is exceptionally high. Such a high figure may reflect a bias in our sample due to selected referral of patients with poor acuity, and therefore the proportion with poor outcome may be higher than would be expected. Furthermore, the series of patients included in this review is not continuous, because cases referred to us with acute disease but good vision were not followed up to the resolution of disease.

The purpose of this review was to identify those features indicating risk of a poor outcome. Although the clinical presentation of APMPPE is distinctive, it may be precipitated by more than one primary disorder. Swelling of the pigment epithelium and focal hypofluorescence during the early stage of fluorescein angiography occurs in a variety of circumstances such as eclampsia, ${ }^{33}$ accelerated hypertension, ${ }^{34}$ giant cell arteritis, ${ }^{35}$ Goodpasture's syndrome ${ }^{36}$ disseminated intravascular coagulopathy, ${ }^{37}$ sickle cell disease, ${ }^{38}$ non-Hodgkin lymphoma, ${ }^{39}$ scleroderma ${ }^{40}{ }^{2 y m e}$ disease ${ }^{41}$ syphilis ${ }^{42}$ and schistosomiasis. ${ }^{43}$ These conditions were excluded in our patients with poor outcome on the basis of history, associated systemic findings and laboratory tests. In all these situations it is believed that there is defective choroidal perfusion and focal ischaemic swelling of the pigment epithelium. Similar pathogenetic mechanisms are believed to pertain in APMPPE in that there is considerable evidence in favour of an inflammatory process that leads to closure of preterminal arterioles of the choriocapillaris and focal choroidal ischaemia. ${ }^{1,15,16,21,22,29,44}$ The leakage of fluorescein from a choroidal vein observed in a case with poor outcome (Fig. $3 \mathrm{e}-\mathrm{g}$ ) provides evidence of a vascular inflammatory disease and shows that choroidal vasculitis may not be limited to the choroidal arterioles or choriocapillaris.

If APMPPE results from choroidal ischaemia the functional outcome may be determined by the nature and severity of the precipitating disorder, and the ability of the eye to recover from the ischaemic insult. The possibility of more than one precipitating disorder is suggested by the variability of clinical associations, such as vasculitis affecting ocular structures other than the choriocapillaris, 7,9,10,12,14,15,19,20,28,45 multisystem involvement ${ }^{4,19,21-27}$ and even death. ${ }^{46}$ The disease at the level of the retinal pigment epithelium also varies from one patient to another. Unilateral disease, asynchronous involvement of the two eyes separated by as much as several years and recurrences are unusual but well recorded. 2,3,8,9-12,14,16,48 These observations imply that the clinical spectrum of APMPPE is broader than initially described. ${ }^{12,16,30,47}$ Our patients with poor final vision had unusual features, and may have had a precipitating disorder different from that in which the outcome is good.

The ability of an eye to withstand ischaemic damage may be determined by the patency of shunts between choroidal arteries or veins ${ }^{48}$ or the potential for retrograde flow from adjacent unaffected lobules, ${ }^{49}$ which may vary from one subject to another and with age. ${ }^{50}$ The poor outcome in the oldest patient may be a consequence of age-related change, but the average age of those with poor final vision was not different from that of the group as a whole.

It is evident that APMPPE is not a condition with universally good outcome and caution should be exercised when determining the prognosis in cases of APMPPE in which there is foveal involvement and severe visual loss, particularly if atypical features are associated.

S.P. was supported by Lady Allerton Fellowship, 1992-3.

\section{REFERENCES}

1. Savino PJ, Weinberg RJ, Yassin JG, Pilkerton AR. Diverse manifestations of acute posterior multifocal placoid pigment epitheliopathy. Am J Ophthalmol 1974;77:659-62.

2. Ryan SJ, Maumenee AE. Acute posterior multifocal placoid pigment epitheliopathy. Am J Ophthalmol 1972;74:1066-74.

3. Wolf MD, Alward WLM, Folk JC. Long-term visual function in acute posterior multifocal placoid pigment epitheliopathy. Arch Ophthalmol 1991;109:800-3.

4. Holt WS, Regan CDJ, Trempe C. Acute posterior multifocal placoid pigment epitheliopathy. Am J Ophthalmol 1976;81:403-12.

5. Azar P Jr, Gohd RS, Waltman D, Gitter KA. Acute posterior multifocal placoid pigment epitheliopathy associated with an adenovirus type 5 infection. Am $\mathbf{J}$ Ophthalmol 1975;80:1003-5.

6. Gass JD. Acute posterior multifocal placoid pigment epitheliopathy. Arch Ophthalmol 1968;80:177-85.

7. Fitzpatrick PJ, Robertson DM. Acute posterior multifocal placoid pigment epitheliopathy. Arch Ophthalmol 1973;89:373-6.

8. Annesley WH, Tomer TL, Shields JA. Multifocal placoid pigment epitheliopathy. Am J Ophthalmol 1973;76:511-8.

9. Murray SB. Acute posterior multifocal placoid pigment epitheliopathy. Not so benign? Trans Ophthalmol Soc UK 1979;99:497-500.

10. Damato BE, Nanjiani M, Foulds WS. Acute posterior multifocal placoid pigment epitheliopathy: a follow up study. Trans Ophthalmol Soc UK 1983;103:517-22.

11. Williams DF, Mieler WF. Long-term follow-up of acute multifocal posterior placoid pigment epitheliopathy. $\mathrm{Br}$ J Ophthalmol 1989;73:985-90.

12. Gass JDM. Acute posterior multifocal placoid pigment epitheliopathy: a long-term follow-up. In: Fine SL, Owens SL, editors. Management of retinal vascular and macular disorders. Baltimore: Williams and Wilkins, 1983:176-81.

13. Saroux H, Pelosse B. Acute posterior multifocal placoid pigment epitheliopathy: a long-term followup. Ophthalmologica 1987;194:161-3. 
14. Lyness AL, Bird AC. Recurrences of acute posterior multifocal placoid pigment epitheliopathy. Am J Ophthalmol 1984;98:203-7.

15. Kirkham TH, ffytche TJ, Sanders MD. Placoid pigment epitheliopathy with retinal vasculitis and papillitis. Br J Ophthalmol 1972;56:875-80.

16. Young NJA, Bird AC, Sehmi K. Pigment epithelial diseases with abnormal choroidal perfusion. Am J Ophthalmol 1980;90:607-18.

17. Keunen JEE, van Meel GJ, van Norren D, Smith VC, Pokorny J. Retinal densitometry in acute posterior multifocal placoid pigment epitheliopathy. Invest Ophthalmol Vis Sci 1989;30:1515-21.

18. Lewis RA, Martonyi CL. Acute posterior multifocal placoid pigment epitheliopathy: a recurrence. Arch Ophthalmol 1975;93:235-8.

19. Savino PJ, Weinberg RJ, Yassin JG, Pilkerton AR. Diverse manifestations of acute posterior multifocal placoid pigment epitheliopathy. Am J Ophthalmol 1974;77:659-62.

20. Jenkins RB, Savino PJ, Pilkerton AR. Placoid pigment epitheliopathy with swelling of the optic discs. Arch Neurol 1973;29:204-5.

21. van Buskirk FM, Lessell S, Friedman E. Pigmentary epitheliopathy and erythema nodosum. Arch Ophthalmol 1971;85:369-72.

22. Deutman AF, Oosterhuis JA, Boen-Tan TN, Aan De Kerk AL. Acute posterior multifocal placoid pigment epitheliopathy: pigment epitheliopathy or choriocapillaritis? Br J Ophthalmol 1972;56:863-74.

23. Jacklin HN. Acute posterior multifocal placoid pigment epitheliopathy and thyroiditis. Arch Ophthalmol 1977;95:995-7.

24. Priluck IA, Robertson DM, Buettner H. Acute posterior multifocal placoid pigment epitheliopathy: urinary findings. Arch Ophthalmol 1981;99:1560-2.

25. Bullock JD, Fletcher RL. Cerebrospinal fluid abnormalities in acute posterior multifocal placoid pigment epitheliopathy. Am J Ophthalmol 1977;84:45-9.

26. Sigelman J, Beherens M, Hilala S. Acute posterior multifocal placoid pigment epitheliopathy associated with cerebral vasculitis and homonymous hemianopia. Am J Ophthalmol 1979;88:919-24.

27. Smith CH, Savino PJ, Beck RW. Acute posterior multifocal placoid pigment epitheliopathy and cerebral vasculitis. Arch Neurol 1983;40:48-50.

28. Isashiki M, Yamashita T, Ohba N. Acute posterior multifocal placoid pigment epitheliopathy associated with diffuse retinal vasculitis and late haemorrhagic macular detachment. Br J Ophthalmol 1986;70:255-9.

29. Bird AC, Hamilton AM. Placoid pigment epitheliopathy presenting with bilateral serous retinal detachment. Br J Ophthalmol 1972;56:881-6.

30. Wright BE, Bird AC, Hamilton AM. Placoid pigment epitheliopathy and Harada's disease. $\mathrm{Br} \mathrm{J}$ Ophthalmol 1978;62:609-21.

31. Young NJA, Bird AC, Sehmi K. Pigment epithelial diseases with abnormal choroidal perfusion. Am J Ophthalmol 1980;90:607-18.
32. Gass JDM. Stereoscopic atlas of macular diseases. 3rd ed. St Louis: CV Mosby, 1987:136-44.

33. Gitter KA, Houser BP, Sarin LK, Justice J Jr. Toxaemia of pregnancy. An angiographic interpretation of fundus changes. Arch Ophthalmol 1968;80:449.

34. Friedman E, Smith TR, Kuwabara T, Beyer CK. Choroidal vascular patterns in hypertension. Arch Ophthalmol 1964;71:842.

35. Foulds WS, Lee WR, Taylor WOG. Clinical and pathological aspects of choroidal ischemia. Trans Ophthalmol Soc UK 1971;91:323.

36. Jampol LM, Lahav M, Albert DM, Craft J. Ocular clinical findings and basement membrane changes in Goodpasture's syndrome. Am J Ophthalmol 1975; 79:452.

37. Cogan DG. Ocular involvement in disseminated intravascular coagulopathy. Arch Ophthalmol 1975; 93:1.

38. Condon PI, Serjeant GR, Ikeda H. Unusual chorioretinal degeneration in sickle cell disease: possible sequelae of posterior ciliary vessel occlusion. $\mathrm{Br} \mathrm{J}$ Ophthalmol 1973;57:81.

39. Gass JDM. Stereoscopic atlas of macular diseases. 3rd ed. St Louis: CV Mosby, 1987:196-9.

40. Grennan DM, Forrester J. Involvement of the eye in SLE and scleroderma: a study using fluorescein angiography in addition to clinical ophthalmic assessment. Ann Rheum Dis 1977;36:152-6.

41. Bodine RS, Marino J, Camisa TJ, Salvate AJ. Multifocal choroiditis with evidence of Lyme disease. Ann Ophthalmol 1992;24:169-73.

42. Gass JDM, Braunstein RA, Chenoweth RG. Acute syphilitic posterior placoid chorioretinitis. Ophthalmology 1990;97:1288-97.

43. Dickinson AJ, Rosenthal AR, Nicholson KG. Inflammation of the retinal pigment epithelium: a unique presentation of ocular schistosomiasis. $\mathrm{Br} \mathrm{J}$ Ophthalmol 1990;74:440-2.

44. Spaide RF, Yannuzzi LA, Slakter J. Choroidal vasculitis in acute posterior multifocal placoid pigment epitheliopathy. Br J Ophthalmol 1991;75:685-7.

45. Charteris DG, Khanna V, Dhillon B. Acute posterior multifocal placoid pigment epitheliopathy complicated by central retinal vein occlusion. $\mathrm{Br} \mathbf{J}$ Ophthalmol 1989;73:765-8.

46. Wilson CA, Choromokos EA, Sheppard R. Acute posterior multifocal placoid pigment epitheliopathy and cerebral vasculitis. Arch Ophthalmol 1988;106:796-800.

47. Gaudric A, Coscas G, Bird AC. Choroidal ischemia Am J Ophthalmol 1982;94:489-98.

48. Yoneya S, Tso MOM. Angioarchitecture of the human choroid. Arch Ophthalmol 1987;105:681-7.

49. Ernest JT, Stern WH, Archer DB. Submacular choroidal circulation. Am J Ophthalmol 1976; $81: 574-82$.

50. Sarks SH. Changes in the region of the choriocapillaris in ageing and degeneration. In: XXIII Concilium Ophthalmol, Kyoto, 1978;228-38. 